\title{
Glucocorticoid counteracts the suppressive effect of tumor necrosis factor- $\alpha$ on the surge of luteinizing hormone secretion in rats
}

\author{
Takashi Matsuwaki, Masatoshi Suzuki, Keitaro Yamanouchi and \\ Masugi Nishihara \\ Department of Veterinary Physiology, Veterinary Medical Science, The University of Tokyo, Tokyo 113-8657, Japan \\ (Requests for offprints should be addressed to M Nishihara; Email: amnishi@mail.ecc.u-tokyo.ac.jp)
}

\begin{abstract}
We have previously reported that tumor necrosis factor- $\alpha$ $(\mathrm{TNF}-\alpha)$ suppressed pulsatile secretion of luteinizing hormone (LH) in adrenalectomized (ADX) rats, which was restored by replacement of glucocorticoid. In the present study, we examined the role of glucocorticoid in inducing the preovulatory LH surge under conditions of infectious stress. Intravenous injection of TNF- $\alpha(1 \mu \mathrm{g})$ into the proestrous rats at $1300 \mathrm{~h}$ attenuated the LH surge and decreased the number of oocytes ovulated. The inhibitory effect of TNF- $\alpha$ on the LH surge was blocked by pretreatment with indomethacin, suggesting that the
\end{abstract}

effects of TNF- $\alpha$ were mediated by prostaglandins (PGs). On the other hand, ADX markedly enhanced the inhibitory effect of TNF- $\alpha$ on the LH surge and subsequent ovulation, which was almost completely restored by pretreatment with a subcutaneous injection of corticosterone $(10 \mathrm{mg})$. These results suggest that glucocorticoid counteracts the inhibitory effect of the cytokines on the preovulatory LH surge by suppressing PG synthesis, and thereby helps to maintain reproductive function under infectious stress conditions.

Journal of Endocrinology (2004) 181, 509-513

\section{Introduction}

Infectious stress exerts a broad influence on the neuroendocrine system, resulting in the activation of the hypothalamic-pituitary-adrenal (HPA) axis and the suppression of the hypothalamic-pituitary-gonadal axis. There are many reports suggesting that the former is the cause of the latter: for example, both corticotropin-releasing hormone (CRH) (Rivier \& Vale 1984, Rivier et al. 1986, Williams et al. 1990) and glucocorticoid (Baldwin 1979, Briski \& Sylvester 1994, McGivern \& Redei 1994) have been shown to suppress pulsatile luteinizing hormone (LH) secretion in rats and monkeys. We have previously shown, however, that suppression of the hypothalamic gonadotropin-releasing hormone $(\mathrm{GnRH})$ pulse generator activity by tumor necrosis factor- $\alpha$ (TNF- $\alpha$ ), which is one of the major cytokines responsible for the coordination of host defence mechanisms (Michie et al. 1988, Sanna et al. 1995, Yoo et al. 1997b), was enhanced by $\alpha$-helical CRH, a CRH receptor antagonist (Yoo et al. 1997a). In addition, we have also shown that adrenalectomy (ADX) enhanced the inhibitory effect of TNF- $\alpha$ on pulsatile LH secretion in ovariectomized rats, and that the secretion was completely restored by the replacement of corticosterone (Matsuwaki et al. 2003). From these results, we hypothesize that the activation of the HPA axis plays a role in maintaining LH pulses under infectious stress conditions.
In addition to the pulsatile secretion, $\mathrm{LH}$ is secreted in a surge fashion during the preovulatory period. These two methods of LH secretion appear to be governed by two intrinsically different neuronal systems - the GnRH pulse generator and the $\mathrm{GnRH}$ surge generator respectively (Nishihara et al. 1999). In fact, the effects of stress on the LH pulse differ from those on the LH surge, and are affected by sex steroids (Cagampang et al. 1991). For example, immobilization (Hashimoto et al. 1990, Kam et al. 2000) and injection of interleukin-1 (Rettori et al. 1991, MohanKumar et al. 2002) suppress both the LH pulse and the LH surge, while hypoglycemia inhibits only the LH pulse (Cagampang et al. 1990, Kawaguchi et al. 1998) in rats. In addition, there are reports demonstrating that glucocorticoid suppresses the LH pulse in rats (Baldwin 1979, Briski \& Sylvester 1994) and monkeys (McGivern \& Redei 1994), but does not affect the LH surge in rats (Sridaran \& Blake 1980) and cows (Dobson \& Smith 2000). These observations suggest that stress and/or glucocorticoid may differently affect $\mathrm{GnRH}$ pulse versus surge generators. It is therefore necessary to reveal the effects of glucocorticoid on the LH surge in gonad-intact rats under stress conditions in order to understand the physiological significance of glucocorticoid in maintaining reproductive function.

In the present study, to elucidate the role of glucocorticoid in inducing the LH surge under conditions of 
infectious stress, we examined the LH surge and subsequent ovulation following TNF- $\alpha$ injection, and the effect of ADX and corticosterone replacement on them. In addition, since it has been shown that prostaglandins (PGs), at least partially, mediate the suppressive effect of TNF- $\alpha$ on LH pulses (Yoo et al. 1997a) and that glucocorticoid inhibits PG synthesis (Hirata et al. 1987), we also examined the possible involvement of PGs in the effects of TNF- $\alpha$ on the LH surge.

\section{Materials and Methods}

\section{Animals}

Female rats of the Wistar-Imamichi strain were obtained from the Imamichi Institute for Animal Reproduction (Tsuchiura, Japan). The animals were maintained under controlled lighting conditions (lights on 0500-1900 h) and given free access to food and water. A number of the animals were adrenalectomized (ADX) under ether anesthesia at 8 weeks of age (body weight $230-250 \mathrm{~g}$ ). For ADX animals, $0.85 \%$ saline was given as drinking water. The rats were subjected to the following experiments after at least 1 week of recovery. All of the experiments were carried out at the age of 9 to 11 weeks. The experiments were conducted according to the Guidelines for the Care and Use of Laboratory Animals, Graduate School of Agriculture and Life Sciences, the University of Tokyo.

\section{Experimental procedures}

All of the intact $(n=15)$ and ADX $(n=15)$ rats used in the present study showed at least two successive 4-day estrous cycles, which were confirmed by their vaginal smears. The day before the experiments, a silastic cannula was inserted into the jugular vein under ether anesthesia. The distal end of the cannula was tunneled subcutaneously to the back of the neck. On the day of the experiment, i.e. the day of proestrus, the animals were moved to the experimental room and allowed at least $2 \mathrm{~h}$ for adaptation. A blood sample $(200 \mu \mathrm{l})$ was withdrawn through the indwelling jugular cannula from freely moving animals without anesthesia at 1-h intervals from $1200 \mathrm{~h}$ to $1900 \mathrm{~h}$. After the withdrawal of each blood sample, an equal volume of heparinized saline $(10 \mathrm{U} / \mathrm{ml})$, in which erythrocytes were suspended, was replaced through the cannula. At $1200 \mathrm{~h}$, five ADX animals were subcutaneously injected with corticosterone (Wako, Osaka, Japan; $10 \mathrm{mg} / 0 \cdot 3 \mathrm{ml}$ sesame oil). At $1300 \mathrm{~h}$, ten ADX animals including those pretreated with corticosterone were administered TNF- $\alpha$ (R \& D Systems, Minneapolis, MN, USA; $1 \mu \mathrm{g} / 50 \mu \mathrm{l}$ saline) through the indwelling jugular cannula. Ten intact rats were also treated with TNF- $\alpha$ at $1300 \mathrm{~h}$; five of them had been intravenously injected with indomethacin (Cayman Chemical Company, Ann Arbor, MI, USA;
$1 \mathrm{mg} / 100 \mathrm{~g}$ body weight), a PG synthesis inhibitor, $10 \mathrm{~min}$ before the injection of TNF- $\alpha$. The remaining five intact and five ADX animals received saline at $1300 \mathrm{~h}$. The collected blood samples were allowed to clot for 1-2 h at room temperature and centrifuged at $5000 \mathrm{~g}$ for $15 \mathrm{~min}$. The separated serum was stored at $-80{ }^{\circ} \mathrm{C}$ until assayed. Between $0800 \mathrm{~h}$ and $1000 \mathrm{~h}$ on the next day, i.e. the day of estrus, the number of oocytes in the ampulla of the oviduct of both sides was counted.

\section{Hormone assay}

Serum concentrations of $\mathrm{LH}$ and corticosterone were measured with a rat LH RIA kit and a rat corticosterone RIA kit (Amersham Pharmacia Biotech, Piscataway, NJ, USA) respectively. The intra- and interassay coefficients of variation for LH assays, which were calculated from five replicated determinations for a pool of rat serum containing $12 \cdot 9 \mathrm{ng} / \mathrm{ml} \mathrm{LH}$, were $4 \cdot 1 \%$ and $5 \cdot 8 \%$ respectively. For corticosterone, the intra- and interassay coefficients of variation, which were calculated from five replicate determinations for a pool of rat serum containing $231.5 \mathrm{ng} / \mathrm{ml}$ corticosterone, were $7 \cdot 4 \%$ and $11 \cdot 8 \%$ respectively.

\section{Statistical analysis}

The data were statistically analyzed by one-way factorial ANOVA followed by post-hoc comparison of Scheffe's test between the two groups. Differences were considered significant at $P<0 \cdot 05$.

\section{Results}

Changes in serum LH levels in the afternoon of proestrus are shown in Fig. 1. Table 1 shows the LH concentrations at $1200 \mathrm{~h}$ and at the peak of the surge, and the number of oocytes in both oviducts the next morning. Serum LH levels at $1200 \mathrm{~h}$ were not different among all the experimental groups. When TNF- $\alpha$ was injected into intact rats, the LH surge tended to be suppressed, although not significantly, and the number of oocytes ovulated was significantly decreased. This inhibitory effect of TNF- $\alpha$ on the LH surge was completely blocked by pretreatment with indomethacin, whereas no oocytes were detected in any of the animals pretreated with indomethacin. Although ADX did not affect the LH surge and the number of oocytes ovulated, injection of TNF- $\alpha$ into the ADX animals almost entirely suppressed the LH surge. In addition, four out of the five ADX animals injected with TNF- $\alpha$ had died by the next morning, and no oocytes were observed in the oviduct of the remaining animal. When corticosterone was injected $1 \mathrm{~h}$ before TNF- $\alpha$ injection in ADX animals, the $\mathrm{LH}$ surge was restored and the number of oocytes in the oviducts was not different 


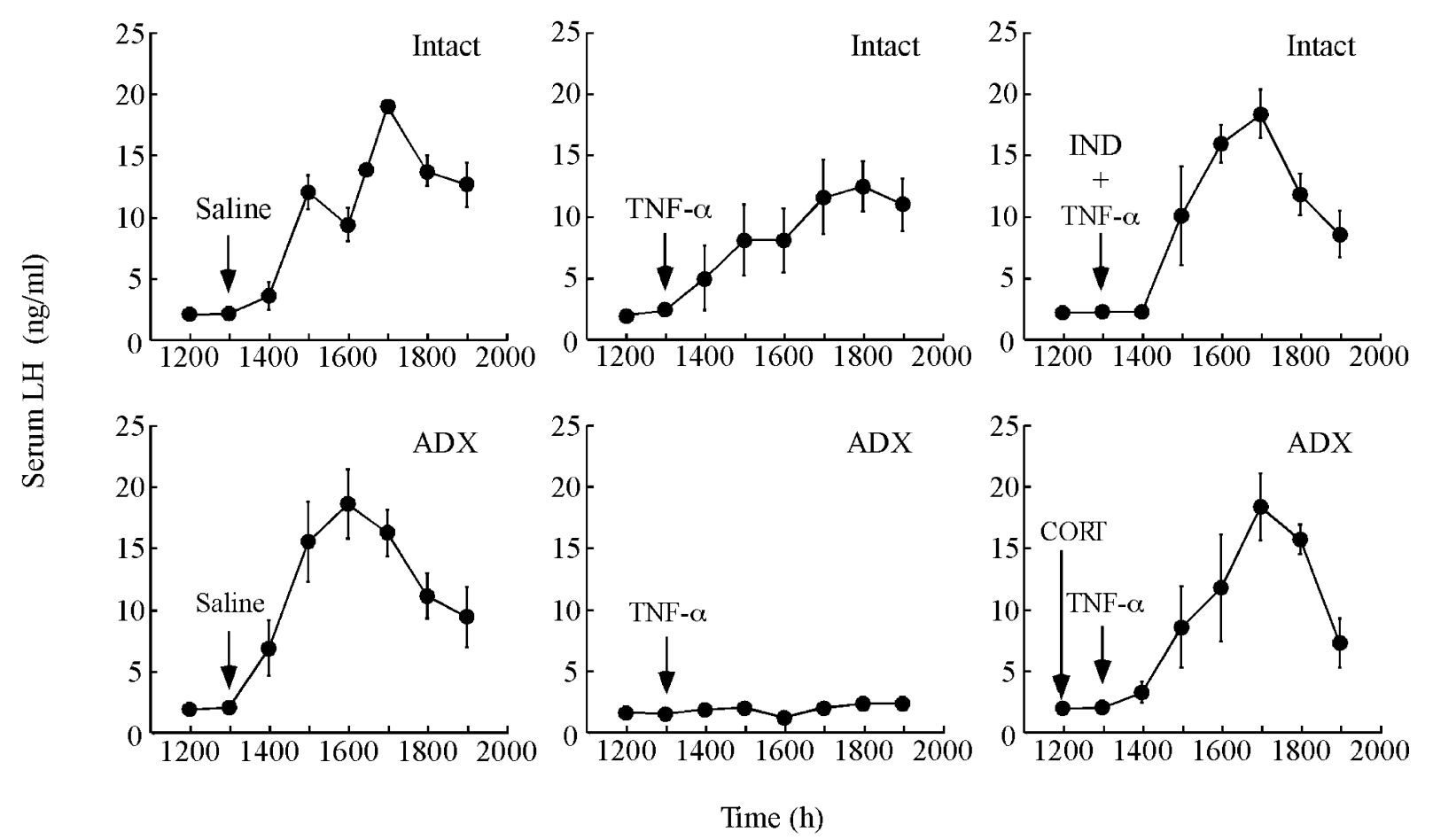

Figure 1 The effect of TNF- $\alpha$ on the spontaneous surge secretion of $\mathrm{LH}$ in the afternoon of proestrus in both intact and adrenalectomized (ADX) rats. TNF- $\alpha(1 \mu \mathrm{g} / 50 \mu \mathrm{l}$ saline) or saline was injected i.v. at $1300 \mathrm{~h}$. Intact rats were injected i.v. with indomethacin (IND, $1 \mathrm{mg} / 100 \mathrm{~g}$ body weight) $10 \mathrm{~min}$ before the injection of TNF- $\alpha$, and ADX rats were injected s.c. with corticosterone (CORT, $10 \mathrm{mg} / 0 \cdot 3 \mathrm{ml}$ sesame oil) at $1200 \mathrm{~h}$. Each point and vertical bar represent the mean \pm S.E. $(n=5)$.

from that of intact animals. As shown in Fig. 2, the serum corticosterone concentration reached a peak $(510 \cdot 9 \mathrm{ng} /$ $\mathrm{ml}) 2 \mathrm{~h}$ after corticosterone injection in ADX rats; this value was not significantly different from the peak value $(439 \cdot 7 \mathrm{ng} / \mathrm{ml})$ in intact rats following TNF- $\alpha$ injection.

\section{Discussion}

In the present study, injection of TNF- $\alpha$ at $1300 \mathrm{~h}$ reduced the peak levels of the LH surge, although not significantly, and significantly decreased the number of oocytes ovulated. Since it has been shown that the LH surge in rats is blocked by the injection of compounds that disrupt neuronal activity during the critical period, which is roughly from $1300 \mathrm{~h}$ to $1600 \mathrm{~h}$ in the afternoon of proestrus (Everett 1989, Stoker et al. 2001), the present result suggests that TNF- $\alpha$ can also decrease the neuronal activity required for the induction of the $\mathrm{LH}$ surge. There seems to be a threshold amount of LH secretion needed to induce ovulation, which is about a fourfold increase above the basal LH concentration (Turgeon \& Barraclough 1973). The ratio of the peak-to-basal LH concentrations in animals injected with TNF- $\alpha$ was $6 \cdot 3$, while it was $10 \cdot 2$ in control animals in this study. The LH concentration in the TNF- $\alpha$-injected animals may not have reached the level necessary to induce normal ovulation, although it exceeded the threshold level.

Table 1 Serum LH concentrations in the afternoon of proestus and the number of oocytes in the oviducts the next morning (estrus).

Values are means \pm S.E. $(n=5)$

\begin{tabular}{|c|c|c|c|c|c|c|}
\hline & Intact & Intact + TNF- $\alpha$ & Intact + IND + TNF- $\alpha$ & ADX & ADX + TNF- $\alpha$ & $\mathrm{ADX}+\mathrm{CORT}+\mathrm{TNF}-\alpha$ \\
\hline \multicolumn{7}{|l|}{ Serum LH (ng/ml) } \\
\hline At $1200 \mathrm{~h}$ & $2 \cdot 1 \pm 0 \cdot 2^{\mathrm{a}}$ & $1 \cdot 9 \pm 0 \cdot 2^{\mathrm{a}}$ & $2 \cdot 2 \pm 0 \cdot 2^{a}$ & $1 \cdot 8 \pm 0 \cdot 2^{\mathrm{a}}$ & $1 \cdot 6 \pm 0 \cdot 2^{\mathrm{a}}$ & $2 \cdot 0 \pm 0 \cdot 2^{\mathrm{a}}$ \\
\hline At the peak & $19 \cdot 0 \pm 0 \cdot 3^{a}$ & $12 \cdot 4 \pm 2 \cdot 0^{\mathrm{b}}$ & $18 \cdot 4 \pm 2 \cdot 0^{\mathrm{a}}$ & $18 \cdot 6 \pm 2 \cdot 8^{\mathrm{a}, \mathrm{b}}$ & $2 \cdot 0 \pm 0 \cdot 1^{\mathrm{c}}$ & $18 \cdot 3 \pm 2 \cdot 7^{a}$ \\
\hline Number of oocytes ovulated & $16 \cdot 2 \pm 0 \cdot 5^{\mathrm{a}}$ & $7 \cdot 2 \pm 2 \cdot 1^{b}$ & 0 & $15 \cdot 4 \pm 0 \cdot 9^{a}$ & NA & $14 \cdot 4 \pm 0 \cdot 5^{a}$ \\
\hline
\end{tabular}

Values with different lettters in each line are significantly different $(P<0 \cdot 05$, ANOVA followed by Scheffe's test).

IND, indomethacin; CORT, corticosterone; NA, not available. 


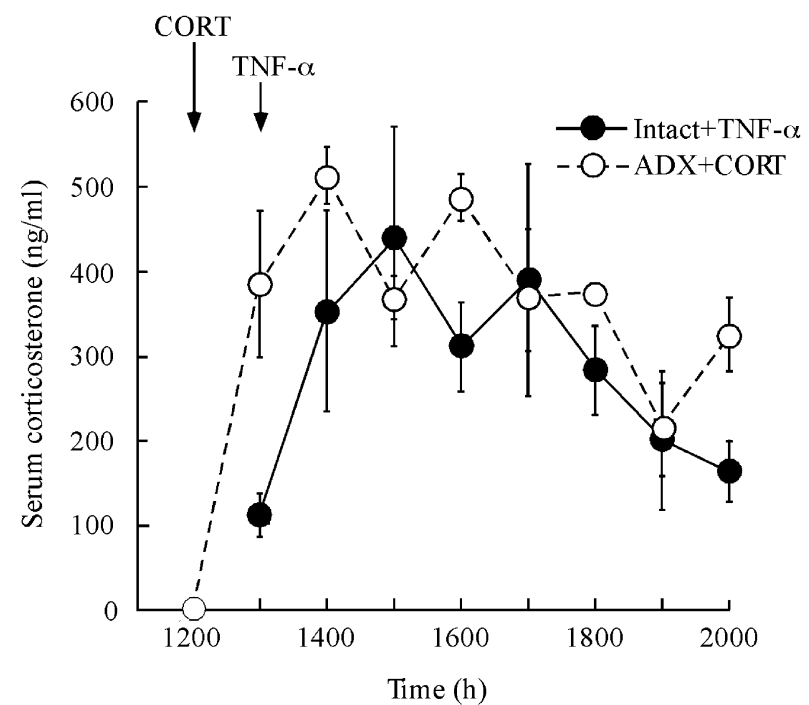

Figure 2 Serum concentrations of corticosterone following i.v. injection of TNF- $\alpha(1 \mu \mathrm{g} / 50 \mu \mathrm{l}$ saline $)$ in intact rats at $1300 \mathrm{~h}$, or s.c. injection of corticosterone (CORT, $10 \mathrm{mg} / 0 \cdot 3 \mathrm{ml}$ sesame oil) in $\mathrm{ADX}$ rats at $1200 \mathrm{~h}$. Each point and vertical bar represents the mean \pm S.E. $(n=4)$.

In the present study, pretreatment with indomethacin almost completely blocked the inhibitory effect of TNF- $\alpha$ on the LH surge. We have previously reported that PGs mediate the suppressive effect of TNF- $\alpha$ on the electrical activity of the hypothalamic GnRH pulse generator (Yoo et al. 1997a). Taken together, it is suggested that PGs play a pivotal role in mediating the inhibitory action of TNF- $\alpha$ on the surge as well as on the pulsatile secretion of LH. In spite of the normal LH surge, oocytes could not be detected in either side of the oviducts in the indomethacin-pretreated animals. This is probably due to the direct action of indomethacin on the ovary as reported previously (Shirota et al. 1998).

ADX did not affect the estrous cycle, the LH surge or subsequent ovulation, consistent with a previous report (Sridaran \& Blake 1980). However, ADX animals seemed to be much more susceptible to TNF- $\alpha$ because the LH surge was not observed in any of the ADX animals injected with TNF- $\alpha$, and most of them died by the next morning. Pretreatment with corticosterone almost completely blocked the effect of ADX; all of the animals injected with corticosterone survived with a normal LH surge and ovulation. The serum profile of corticosterone following its injection into ADX animals was similar to that following TNF- $\alpha$ injection into intact animals, indicating that glucocorticoid plays an important role in inducing the $\mathrm{LH}$ surge and subsequent ovulation, as well as the LH pulse in ovariectomized rats (Matsuwaki et al. 2003), under infectious stress conditions. Although the neuronal systems inducing the LH pulse and surge, respectively, are regarded as intrinsically different (Nishihara et al. 1999), glucocorticoid could counteract the suppressive effects of infectious stress on both systems.

As mentioned above, PGs are involved in mediating the inhibitory effect of TNF- $\alpha$ on the LH surge. On the other hand, glucocorticoid is known to inhibit PG synthesis (Hirata et al. 1987). Taken together, the increase in glucocorticoid secretion probably counteracted the cytokine effects by suppressing PG synthesis in the hypothalamus, and thereby restored the LH surge. Contrary to the present results, there are many studies indicating inhibitory effects of glucocorticoid on reproductive processes in rats (Baldwin 1979, Briski \& Sylvester 1994, McGivern \& Redei 1994). Although further studies are needed to reconcile the contradiction, one of the possible explanations for the difference in the effects of glucocorticoid is the difference in the stressors the animals suffered. Glucocorticoid may preferably interfere with the suppressive effect of stress on reproductive function when the effect of stress is mainly mediated by PGs in the hypothalamus as in the case of infectious stress examined in the present study.

The present study demonstrates that an increase in glucocorticoid levels is a prerequisite for the maintenance of the preovulatory LH surge under infectious stress conditions. Although $\mathrm{CRH}$ has been regarded to be inhibitory towards reproductive function (Rivier \& Vale 1984, Rivier et al. 1986, Williams et al. 1990), we have previously shown that intracerebroventricular injection of $\alpha$-helical CRH enhanced the TNF- $\alpha$-induced suppression of the GnRH pulse generator (Yoo et al. 1997a). In addition, we have also shown that glucocorticoid maintains pulsatile secretion of $\mathrm{LH}$ under infectious stress conditions (Matsuwaki et al. 2003). Taken together, we conclude that the activation of the HPA axis and the resultant increase in glucocorticoid levels are physiologically involved in the maintenance of reproductive function, at least under conditions of infectious stress.

\section{Funding}

This work was supported by a Grant-in-Aid for Scientific Research, the Japan Society for the Promotion of Science (13854007, to $\mathrm{M} \mathrm{N})$.

\section{References}

Baldwin DM 1979 The effect of glucocorticoids on estrogendependent luteinizing hormone release in the ovariectomized rat and on gonadotropin secretion in the intact female rat. Endocrinology $105120-128$.

Briski KP \& Sylvester PW 1994 Antagonism of type II, but not type I glucocorticoid receptors results in elevated basal luteinizing hormone release in male rats. Neuroendocrinology 60 601-608.

Cagampang FR, Maeda K, Yokoyama A \& Ota K 1990 Effect of food deprivation on the pulsatile $\mathrm{LH}$ release in the cycling and ovariectomized female rat. Hormone and Metabolic Research 22 269-272. 
Cagampang FR, Maeda KI, Tsukamura H, Ohkura S \& Ota K 1991 Involvement of ovarian steroids and endogenous opioids in the fasting-induced suppression of pulsatile LH release in ovariectomized rats. Journal of Endocrinology 129 321-328.

Dobson H \& Smith RF 2000 What is stress, and how does it affect reproduction? Animal Reproduction Science 6-61 743-752.

Everett JW 1989 Neurobiology of reproduction in the female rat. A fifty-year perspective. Monographs on Endocrinology 32 1-133.

Hashimoto R, Arita J \& Kimura F 1990 LH and PRL secretion in ovariectomized spontaneously hypertensive rats. Acta Endocrinologica $122540-544$.

Hirata F, Stracke ML \& Schiffmann E 1987 Regulation of prostaglandin formation by glucocorticoids and their second messenger, lipocortins. Journal of Steroid Biochemistry 27 1053-1056.

Kam K, Park Y, Cheon M, Son GH, Kim K \& Ryu K 2000 Effects of immobilization stress on estrogen-induced surges of luteinizing hormone and prolactin in ovariectomized rats. Endocrine $\mathbf{1 2}$ 279-287.

Kawaguchi M, Funabashi T \& Kimura F 1998 Insulin-induced hypoglycemia does not impair the surge of luteinizing hormone secretion in the proestrous rat. Neuroscience Letters 256 131-134.

McGivern RF \& Redei E 1994 Adrenalectomy reverses stress-induced suppression of luteinizing hormone secretion in long-term ovariectomized rats. Physiology and Behavior 55 1147-1150.

Matsuwaki T, Watanabe E, Suzuki M, Yamanouchi K \& Nishihara M 2003 Glucocorticoid maintains pulsatile secretion of LH under infectious stress condition. Endocrinology 144 3477-3482.

Michie HR, Manogue KR, Spriggs DR, Revhaug A, O’Dwyer S, Dinarello CA, Cerami A, Wolff SM \& Wilmore DW 1988 Detection of circulating tumor necrosis factor after endotoxin administration. New England Journal of Medicine 318 1481-1486.

MohanKumar SM \& MohanKumar PS 2002 Effects of interleukin-1B on the steroid-induced luteinizing hormone surge: role of norepinephrine in the medial preoptic area. Brain Research Bulletin 58 405-409.

Nishihara M, Takeuchi Y, Tanaka T \& Mori Y 1999

Electrophysiological correlates of pulsatile and surge gonadotrophin secretion. Reviews of Reproduction 4 110-116.

Rettori V, Gimeno MF, Karara A, Gonzalez MC \& McCann SM 1991 Interleukin $1 \alpha$ inhibits prostaglandin E2 release to suppress pulsatile release of luteinizing hormone but not follicle-stimulating hormone. PNAS 88 2763-2767.
Rivier C \& Vale W 1984 Influence of corticotropin-releasing factor on reproductive functions in the rat. Endocrinology 114 914-921.

Rivier C, Rivier J \& Vale W 1986 Stress-induced inhibition of reproductive functions: role of endogenous corticotropin-releasing factor. Science 231 607-609.

Sanna PP, Weiss F, Samson ME, Bloom FE \& Pich EM 1995 Rapid induction of tumor necrosis factor $\alpha$ in the cerebrospinal fluid after intracerebroventricular injection of lipopolysaccharide revealed by a sensitive capture immuno-PCR assay. PNAS 92 272-275.

Shirota M, Watanabe G, Taya K \& Sasamoto S 1998 Effects of indomethacin on the selective release of follicle-stimulating hormone during the period of ovulation in the rat. Journal of Veterinary Medical Science 60 1059-1065.

Sridaran R \& Blake CA 1980 Effects of long-term adrenalectomy on periovulatory increases in serum gonadotrophins and ovulation in rats. Journal of Endocrinology 84 75-82.

Stoker TE, Goldman JM \& Cooper RL 2001 Delayed ovulation and pregnancy outcome: effect of environmental toxicants on the neuroendocrine control of the ovary. Environmental Toxicology and Pharmacology 9 117-129.

Turgeon J \& Barraclough CA 1973 Temporal patterns of LH release following graded preoptic electrochemical stimulation in proestrous rats. Endocrinology 92 755-761.

Williams CL, Nishihara M, Thalabard JC, Grosser PM, Hotchkiss J \& Knobil E 1990 Corticotropin-releasing factor and gonadotropin-releasing hormone pulse generator activity in the rhesus monkey. Electrophysiological studies. Neuroendocrinology $\mathbf{5 2}$ 133-137.

Yoo MJ, Nishihara M \& Takahashi M 1997a Involvement of prostaglandins in suppression of gonadotropin-releasing hormone pulse generator activity by tumor necrosis factor- $\alpha$. Journal of Reproduction and Development 43 181-187.

Yoo MJ, Nishihara M \& Takahashi M $1997 b$ Tumor necrosis factor- $\alpha$ mediates endotoxin induced suppression of gonadotropin-releasing hormone pulse generator activity in the rat. Endocrine Journal 44 $141-148$

Received 18 February 2004

Accepted 2 March 2004

Made available online as an

Accepted Preprint 12 March 2004 